UDC 130.2

LBC 87.52

\title{
HYBRID CULTURE DISCOURSE: PRISONIZATION OF THE CITY (SIBERIAN CASE) ${ }^{1}$
}

\author{
Pavel L. Zaitsev \\ Dostoevsky Omsk State University, Omsk, Russian Federation \\ Svetlana N. Ovodova \\ Dostoevsky Omsk State University, Omsk, Russian Federation
}

\begin{abstract}
The author studies the phenomenon of prizonization distinguished on the basis of essential and stable properties of Soviet and post-Soviet culture. To consider the processes of prisonization the model of M. Foucault is still thought quite relevant. According to Foucault, criminal culture is marginalized, squeezed to the outer colony whenever possible. From the point of view of M. Foucault and the Chicago school of sociology studying segregation and zoning principles in the city, prison is a marginal space. It is forced out of official culture, and social prison practices are considered unacceptable "on the outside". Housekeeping of Siberian cities was organized in a different mode: not being able to reject the criminal culture, society went the way of its processing, connection with the official culture. The article analyzes a significant number of sources telling about the fusion of official and criminal culture in the Siberian text. "Notes from the Dead house" by F. M. Dostoevsky, "Prison Camp: Notes of the Warden" by S. D. Dovlatov, "Kolyma stories" by V. Shalamov, as well as the modern domestic chanson of "Siberian" origin, equally contain a reference to the transition of convict, criminal culture beyond the prison walls. At the level of methodology this study allows us to test the research tools of postcolonialism in Criminal Studies - a research direction that has not yet been fully determined even in Western humanitarianism. The proximity of official and criminal culture gave rise to a special discourse, which can be considered in the optics of hybrid culture H. Bhabha. The methodology developed within the boundaries of the postcolonial approach opens up opportunities for analyzing the current social and cultural situation in Siberian cities.
\end{abstract}

Key words: prizonization, criminal culture, criminal studies, hybrid culture, postcolonial studies, Siberia, Siberian cities.

УДК 130.2

ББК 87.52

\section{ДИСКУРС ГИБРИДНОЙ КУЛЬТУРЫ: ПРИЗОНИЗАЦИЯ ГОРОДА (СИБИРСКИЙ КЕЙС) ${ }^{1}$}

Павел Леонидович Зайцев

Омский государственный университет им. Ф.М. Достоевского, г. Омск, Российская Федерация

\section{Светлана Николаевна Оводова}

Омский государственный университет им. Ф.М. Достоевского, г. Омск, Российская Федерация

Аннотация. В статье рассматривается феномен призонизации, выделяемый на основе существенных и устойчивых свойств советской и постсоветской культуры. Для рассмотрения процессов призонизации достаточно релевантной до сих пор представлялась модель М. Фуко, согласно которому криминальная культура маргинализируется, отторгается и по возможности вытесняется официальной культурой. С точки зрения М. Фуко и чикагской социологической школы, изучающей сегрегацию и принципы зонирования в городе, тюрьма - это маргинальное пространство. Она вытесняется из официальной культуры, 
а социальные тюремные практики считаются недопустимыми «на воле». Складывание быта сибирских городов проходило в ином режиме: не имея возможности отторгнуть криминальную культуру, общество пошло по пути ее переработки, соединения с официальной культурой. В статье приводится анализ значительного количества источников, повествующих о сплаве официальной и криминальной культуры в сибирском тексте. «Записки из Мертвого дома» Ф.М. Достоевского, «Зона: Записки надзирателя» С.Д. Довлатова, «Колымские рассказы» В. Шаламова, а также современный отечественный шансон «сибирского» происхождения в равной степени содержат отсыл к выходу каторжной, криминальной культуры за пределы острожных стен. На уровне методологии это позволяет апробировать в criminal studies - направлении исследований еще не до конца закрепившегося даже в западной гуманитаристике - исследовательский инструментарий постколониализма. Соседство официальной и криминальной культуры породило особый дискурс, что может быть рассмотрено в оптике гибридной культуры Х. Бхабха. Методология, разработанная в границах постколониального подхода, открывает возможности для анализа современной социальной и культурной ситуации в сибирских городах.

Ключевые слова: призонизация, криминальная культура, criminal studies, гибридная культура, постколониальные исследования, Сибирь, сибирские города.

Термин «призонизация» происходит от английского prison (тюрьма), он вполне ясен и в русском словоупотреблении из-за заимствованного ранее слова зона (от греч. жюнз «пояс»). Призонизацией города можно считать влияние языковых, поведенческих норм тюремного, лагерного быта на культуру современной урбосистемы. Еще в 60 -е гг. XX в. в обычном языке широкое распространение получили выражения: «большая зона» (воля), «малая зона» (тюрьмы и лагеря). Проявленность процессов призонизации в нашей стране такова, что сам термин приобретает здесь особое содержание. Ведь часть населения в прямом, а не переносном смысле живет зоной и при зоне. Названия множества городов за Уральским хребтом имеют весьма характерные местные «расшифровки», такие как Омск - «Отдаленное Место Ссылки Каторжников» (Отдаленное Место Сибирской Каторги), Томск - «Таежное Место Сибирской Каторги». В исследовании «Формирование региональной идентичности в современной России» Н. Петров обозначил специфику российских регионов: в отличие от североамериканских штатов, не имеющих официальных символов (животного, растения, девиза), у российских регионов есть прозвища, однозначно связываемые общественным сознанием с тем или иным регионом. Согласно Н. Петрову прозвище Иркутской области «во глубине сибирских руд», Магаданской области - «Зэкия», «Колыма», республики Бурятия - «Острог», республики Мордовия - «Мордовские лагеря» [Гельман, Хопф (ред.) 2003, 171-173]. В каждом крупном городе за Уралом к цент- ральным улицам жмется свое «Чебью» (поселок, описанный в воспоминаниях С. Довлатова), с собственными нормами и обычаями. Описывая быт поселка, Довлатов констатировал «идейный баланс нашего государства, раскинувшегося по обе стороны лагерных заборов»: «Половина его населения - сезонники из бывших зеков. Люди, у которых дружба и ссора неразличимы по виду. Годами они тянули срок. Затем надевали гражданское тряпье, двадцать лет пролежавшее в каптерках. Уходили за ворота, оставляя позади холодный стук штыря. И тогда становилось ясно, что желанная воля есть знакомый песенный рефрен, не больше. <..>> В результате поселок жил лагерным кодексом. Население его щеголяло блатными повадками. И даже третье поколение любой семьи кололось морфином. А заодно тянуло «дурь» и ненавидело конвойные войска. И не стоило появляться здесь выпившему чекисту. Над головой его, увенчанной красным околышем, быстро собирались тучи. За спиной его хлопали двери. И хорошо, если парень был не один...» [Довлатов 2006, 54-55]. Схожие нормы жизни отличают омские «Чикаго», «Нефтяники», «Амур», «Северные», «Порт-Артур», «Сталинск», «Сахалин» (неофициальные названия омских районов).

Общим местом при рассмотрении проявлений призонизации в больших городах в зарубежном и отечественном социально-гуманитарном знании является изучение субкультур городских гетто, акцентуация смыслов отсечения, обособления, противостояния. Примером такого исследования является работа, 
проделанная А. Олейником и направленная на выявление норм и принципов функционирования тюремного сообщества [Олейник 2001]. Таким образом, колония, как и гетто, становится своеобразной внутренней социальнокультурной антитезой постмодернистки понимаемому современному городу, сосредоточием протестной антикультуры, отношение к которой в полной мере реализовано в символике белой бетонной стены, отделяющей 13 район Парижа от остального города в художественном фильме «13 район», сценаристом которого выступил Люк Бессон.

Исследовательские проблемы, связанные с увеличением преступности, всегда были востребованы в академических кругах. Вопросы призонизации рассматриваются в статье Б.Д. Маккэнна, где он выявляет, как тюрьма повлияла на «The Movement for Black Liberation» (Движение за освобождение «цветных») [MacCann 2018]. Шо Шигиока выявляет, как плохое поведение в школе коррелирует с попаданием в тюрьму [Shigeoka 2018].

На стыке game studies и postcolonial studies рождаются интересные исследовательские проекты, осмысляющие репрезентацию дискурса власти, идентичности в пространстве компьютерной игры. П. Мартин [Martin 2018] изучает, как в японских компьютерных играх отражаются представления о расе, цвете кожи и т. п. П. Мартин проводит идею о том, что в связи с отличием цвета кожи японцев они очень специфическим образом, отличным от европейцев и американцев, изображают людей с черным и белым цветом кожи. Это наиболее ярко репрезентируется в компьютерных играх, где эта разница восприятия антропологических отличий становится наглядной. Например, К. Леван, С. Даунинг [Levan, Downing 2019] изучают симуляцию побега из тюрьмы в компьютерной игре. Игрок предстает в роли заключенного, который находится под наблюдением охраны и должен сбежать из тюрьмы. Симуляция в виртуальной реальности дисциплинарного пространства и интерес к такой игре со стороны свободных граждан является показательным. По нашему мнению, это демонстрирует процессы проникновения дискурса и практик тюремной культуры в «свободную» культуру, что порождает пространства смешения дискурсов и практик обеих культур. Изучение компьютерных игр с позиции постколониального поворота демонстрирует, как в массовую культуру проникают темы колонии и тюрьмы.

Осмысление дискурса тюремной культуры, его отражение в массовой культуре мы находим в статье Л. Спида [Speed 2019]. Он анализирует «Prison Songs» («Тюремные песни»), первый документальный мюзикл в Австралии о тюрьме. Постановка основана на документальных источниках информации и рассказах самих заключенных. Нарратив об опыте участников проекта обретает художественное выражение в песнях, танцах и т. п. В данном контексте также является интересным спектакль «Коробка: Черная комедия» Маркуса Гардли, для организации которого стремятся привлечь местные маргинальные сообщества, демонстрирующие дезадаптивное поведение, для того чтобы они смогли в художественной форме объективировать свой негативный опыт и в дальнейшем осмыслить его.

Гипотеза исследования, предлагаемая авторами данной статьи, заключается в том, что сибирская призонизация не локализована, как явление она наблюдается в социальном и культурном пространстве большого города, пронизывая все его уровни, системы, функциональные зоны без исключения. Тюрьмы, тюремный быт вплетены в историю сибирских городов, являются ее неотъемлемой частью, которая, даже будучи изолирована в дискурсе, проявляется в «народной» расшифровке сложившихся топонимов, городской символики. На карту любого сибирского города может быть нанесена карта исправительных колоний (далее - ИК) УФСИН России.

Цель исследования - выявить и теоретически описать механизмы функционирования призонизации в сибирских городах как формы гибридной культуры.

В качестве методологии в исследовании применяется постколониальный подход, позволяющий осмыслить трансформацию дискурса призонизации в рамках официальной культуры.

История сибирских городов, создававшихся вокруг крепостей, включавших в себя, в том числе и гауптвахты, тюрьмы, бараки каторжан с самого начала подразумевала включенность тюремной специфики в город- 
скую повседневность. Так осваивалась и заселялась Сибирь. Примером здесь может послужить история омского острога, изначально находящегося на территории Омской крепости. По мере того как ветшали ее деревянные здания и строились каменные, «Мертвый дом», описанный Ф.М. Достоевским, сначала переехал в здание в степном бастионе крепости, а после - в отдельный тюремный замок, строительство которого было завершено в 1859 году. Если следовать описанию рождественской службы в «Записках из Мертвого дома», то в остроге не было домового храма: «Между тем в военной казарме приготовлялись к принятию священника. Эта казарма была устроена не так, как другие: в ней нары тянулись около стен, а не посредине комнаты, как во всех прочих казармах, так что это была единственная в остроге комната, не загроможденная посредине. Вероятно, она и устроена была таким образом, чтоб в ней, в необходимых случаях, можно было собирать арестантов. Среди комнаты поставили столик, накрыли его чистым полотенцем, поставили на нем образ и зажгли лампадку. Наконец пришел священник с крестом и святою водою. Помолившись и пропев перед образом, он стал перед арестантами, и все с истинным благоговением стали подходить прикладываться к кресту. Затем священник обошел все казармы и окропил их святою водою» [Достоевский 2008, 169]. В каменном тюремном замке уже была запланирована домовая церковь. В «Справочной книге Омской епархии» Иоанна Голошубина упомянута «Скорбященская церковь» при Омском тюремном замке, построенная в 1860 г. и помещающаяся на втором этаже трехэтажного здания. Церковь была с одним престолом, освященным в честь иконы Божьей Матери «Всех Скорбящих Рaдость». Автор справочника пишет, что в тюрьме есть школа для взрослых заключенных мужчин, учитель которой получает 350 руб. в год от Тюремного Комитета, при тюрьме действует приют для арестантских детей, где они воспитываются и обучаются грамоте. В течение года в церкви бывает до 10 крещений, 3 браков и 16 погребений [Голошубин (ред.) $1914,34]$. Тюремный замок, даже огороженный от внешнего мира трехметровой стеной, выступал одним из градообразующих мест, с обширным хозяйством, не только притягивающим к себе местное население, но и формирующим местное население, как следует из сохранившихся метрических книг. В советское время в постоянно перестраивающемся тюремном замке находилась ИТК-5. В 1994 г. его территория и помещения были закреплены за следственным изолятором. Находящиеся на пересечении центральных улиц города, Орджоникидзе и Кемеровской, строения бывшего тюремного замка, помнившие Ядринцева и Потанина, органично вписаны в городской ландшафт территории, сформировавшейся вокруг них. Если Омск - уездный город строился вокруг появившегося благодаря императорскому указу тюремного замка как одного из ключевых элементов городского пространства, то Омск - промышленный город создавался, в том числе и усилиями заключенных омских колоний.

В советское время существование пояса ГУЛАГ, проходящего через всю Сибирь (Омск, Караганда, Новосибирск, Красноярск, Иркутск), только усилило эту зависимость, если брать в расчет ограничения по территориальной мобильности бывших заключенных (особенно во время Великой Отечественной войны и по ее окончанию). В г. Омске в 1930-е гг. существовали два крупных подразделения Главного управления мест заключения (ГУМЗ) - «Омскстрой» и «ОмЛАГ», которые занимались эвакуацией промышленных предприятий из центральной России и организацией военной промышленности на местах. В Омске для выполнения военных заказов открывались новые колонии, которые изготавливали военное снаряжение, деревянную тару, гранаты, мины и другую продукцию. В августе 1943 г. на базе гаражей ОмЛАГа, который был ликвидирован, создана ИТК-6, одна из старейших действующих в г. Омске колоний. Гаражи за какой-то месяц стали полноценными цехами. В сентябре 1943 г. ИТК-6 приступила к выпуску спецтары для мин, которые производились до самого окончания Великой Отечественной войны.

При современной застройке сибирских городов, росте и развитии их урбоструктуры учреждения ИТК оказываются островами внутри городской агломерации, вокруг которых расположены промышленные предприя- 
тия, селитебная зона жилых домов, торговых комплексов, учреждений культуры, как, например, вокруг ИК-6 в г. Омске, находящийся на улице 3-й Разьезд, связанной с центральной для города улицей Лермонтова, в пешей доступности от нее по улице 27 Линия находится ФКУ ИК-9 УФСИН России по Омской области. Известная благодаря вниманию правозащитников к деятельности учреждения ИК-7 УФСИН России по Омской области [Громова web; В Омске... web] находится в пешей доступности от улицы Нефтезаводской, на которую выходят два корпуса Омского государственного университета им. Ф.М. Достоевского.

Сибирским городам свойственна инкультурация каторжного нарратива, проявляющаяся в выделении памятных мест связанных с известными сибирскими «сидельцами», построении экспозиций провинциальных музеев. В архитектурном комплексе Тобольского кремля особое место занимает «тюремный замок», на базе которого функционирует Музей Сибирской каторги и ссылки. По информации с официального сайта музея: «В ходе экскурсии туристы знакомятся с бытом арестантов дореволюционного и советского периодов, самые смелые гости могут спуститься в мрачное подземелье, сохранившее гнетущую атмосферу заточения. Если вас не пугают рассказы и легенды о призраках, станьте нашим гостем в хостеле "Узник", расположенном в самом центре Тюремного замка. Посетители могут приобрести фирменные сухари и сувениры в тюремной лавке, согреться в чайной "По кругу", сделать памятные снимки в фотозоне» [Тюремный замок web]. Омский государственный литературный музей имени Ф.М. Достоевского предлагает посетителям посидеть на лавках каторжного барака, центральное место экспозиции «Достоевский и Сибирь» занимают ножные кандалы, сайт музея объясняет причину такого решения: «Художественное решение каждого зала акцентирует главную идею экспозиции: показать путь духовных исканий Ф.М. Достоевского сквозь мрак испытаний омской каторги к Горнему свету веры» [Омский государственный литературный музей имени Ф.М. Достоевского web]. Томский мемориальный музей «Следствен- ная тюрьма НКВД» выступает с проектом «восстановления части расстрельного подземного тоннеля и включения его составной частью Мемориального музея, что позволит значительно расширить выставочно-экспозиционные и функциональные возможности Музея» [Мемориальный музей «Следственная тюрьма НКВД» web], становится площадкой для концентрации информации о находившихся в Томской области «почтовых ящиках», закрытых административно-территориальных образованиях (ЗАТО), таких как город Северск (Томск 7) [Город за «колючкой» web]. 8 июля 2014 г. в г. Тюкалинске Омской области главами муниципальных образований семи районов Омской, Тюменской и Новосибирской области была учреждена Ассоциация межмуниципального сотрудничества «Сибирский тракт», в качестве межрегионального туристского проекта «Сибирский тракт» включает в себя четыре действующих туристско-экскурсионных маршрута. По информации с сайта проекта в ходе экскурсии «Уездный город Тюкалинск» планируется посещение комплекса зданий городской тюрьмы, интерактивная экскурсия «Путь каторжан и Музей истории Московско-Сибирского тракта» предполагает кандалы, робу, сопровождение охраны, а автобусно-пешеходный маршрут «Омск - Тюкалинск» предлагает переодевание в арестантские робы, кандалы [Сибирский тракт web].

Особенно интенсивно процессы призонизации происходят в молодежной среде, где это часто носит характер ролевой игры. Мысленно примерить на себя «робу» сидельца, эмоционально пережив возможность расставания со свободой, предлагает городской шансон, точнее его гибридные формы, в которых уже нельзя точно определить жанр композиции. Достаточно показательны здесь популярные на youtube.com треки омских исполнителей: «Вот так я и писал» Жени Сибиряка, описывающий попадание «в лагеря» студента университета, уступившего место за рулем нетрезвой одногруппнице; «За черлакских пацанов» Игоря Сахалина, представляющий рабочий поселок в Омской области местом, где жизнь течет исключительно в понятиях призонизированной культуры. 
Если придерживаться точки зрения психологии, то открытость культуры тюремной теме может быть объяснена по аналогии с открытостью несформированной личности адаптивной или биологической агрессии. По поводу биологической агрессии написано и сказано достаточно много. Так, Л. фон Берталанфи находил в человеческой психике биологические задатки деструктивного поведения, а потому считал адаптивную агрессию естественной и невинной [Берталанфи 1969, 41-44]. В этом же направлении мыслил Э. Фромм, считавший, что в человеческой природе скрываются особые потребности, базирующиеся на конфликте, врожденном человеку противоречивом стремлении одновременно и к безопасности, и к свободе жизненного выбора [Фромм 2008, 138-139]. Ощущение безопасности вызывает тревогу несвободы, ощущение свободы грозит интенсивным переживанием отсутствия безопасности. Между безопасностью и свободой может быть помещено и описано большинство экзистенциалов, на которых строится современная философская антропология: страх, скука, тоска, тошнота, наслаждение, ужас. Проходя через них, испытывая в той или иной форме экзистенциалы как переживания, человек по-своему адаптируется в мире, научается жить между беззащитной свободой и защищающей необходимостью. Насколько этот подход может быть спроецирован на призонизированную культуру? Мы признаем, что призонизированная культура пронизана агрессией, ей присущи адаптивные качества; примеры городского шансона полны переживаемых экзистенциалов. Однако более перспективной объяснительной схемой нам представляется методология М. Фуко.

С точки зрения М. Фуко и чикагской социологической школы, изучающей сегрегацию и принципы зонирования в городе, тюрьма это маргинальное пространство [Фуко 2016]. Она вытесняется из официальной культуры, а социальные тюремные практики считаются недопустимыми «на воле». Однако, как показывают приведенные нами выше примеры, длительное сосуществование двух культур, при котором официальная культура не вытесняет криминальную культуру во внешние колонии (например, как это происходило в Евро- пе), а вынуждена мириться с ней в колониях внутренних, создавая внутри страны пространства изоляции, вызывает к жизни феномен гибридной культуры, самым причудливым образом включая в себя практики обеих. Исторический опыт Западной Европы демонстрирует, как маргинальные элементы вытеснялись из страны посредством переселения в подвластные колониальные страны, таким образом, создавались внешние колонии. Отечественный опыт отличает иной способ взаимодействия с маргиналами: в связи с наличием больших просторов люди выселялись в отдельные области или поселения на периферии, что создавало внутренние колонии, которые неизбежно влияли на официальную культуру, меняли ее, способствовали формированию гибридных форм культуры.

Тема гибридной культуры традиционно связывается с дискурсом о национальной и культурной идентичности. Тексты, написанные с использованием методологии postcolonial studies, анализируют проблемы идентификации человека, попавшего в пространство чужой культуры. Postcolonial studies, возникшие как критическая теория, акцентирующая внимание на наличии господства и подчинения в культуре, оказала влияние на методологию философии и теории культуры. Исследователи деконструируют колониализм и его властные образы и пытаются воссоздать самобытный облик подчинявшейся культуры или социальной группы. Дискурс постколониализма вызвал к жизни два связанных между собой явления, часто воспринимаемых как противоположные: акцент на разграничение и размывание границ между странами, культурами, расами, классами, гендерными ролями. Все это не могло не обострить проблему поиска идентичности и устойчивых оснований собственной самости. Акцент на границе в восприятии культуры проявляется в демонстрации отличий, обособляющих культуру от прочих, ее уникальность при таком подходе исходит не от культурного ядра, а от культурного предела. B postcolonial studies борьба сообщества за свою самобытность в пространстве рухнувших империй осмысляется прежде всего как попытка отстоять свою идентичность в дискурсивном пространстве. Концепты нации, расы, локальных образов культуры, со- 
бранные под влиянием и при участии «метрополии», деконструируются подготовленной в «метрополии» национальной интеллигенцией; проблематизируются вопросы языков культуры и способов их функционирования.

Понятие гибридной культуры вводит в своих работах Х. Бхабха [Bhabha 2004]. Ее формирование происходит на границе с доминирующей и колонизируемой культурой. В ходе колонизации коренная культура вынужденно трансформируется, подстраиваясь под культуру империи. Вновь сформированная культура отличается и от культуры «метрополии» и от исконной культуры, она приобретает черты гибридности, так как формируется на стыке двух культур в пространстве диалога и подавления и впитывает в себя дискурсы и практики разных культур. Понятие гибридной культуры используется для объяснения моделей поведения, формирующихся в результате миграций в ситуации мультикультурализма. Разрыв репрезентаций идентичности в рамках гибридной культуры порожден тем, что человеку приходится переключаться с одной системы ценностей на другую. Примером носителей гибридной идентичности являются мигранты, беженцы, представители диаспор и т. п.

Гибридизация культуры продуктивно осмыслялась Х. Бхабха в концептах «другая нация», «другая страна». В работе «Тhe Location of Culture» [Bhabha 2004] он использует такие понятия, как мимикрия, интерстиция, гибридность и ограниченность, чтобы утверждать, что культурное производство всегда наиболее продуктивно, когда оно амбивалентно. При всех вызовах, стоящих за термином «призонизация», мы рискнем предположить в нем не только проблему, но и возможность для Сибирского региона. Замечая, как провинциальные музеи Сибири начинают использовать тему «кандалов», мы не стремимся подчеркнуть этим усугубляющиеся смыслы их маргинализации в «оптике» Х. Бхабха, мы скорее предполагаем здесь поиски точек соприкосновения разных культурных практик. Западная культура крупных городов, выталкивающих из себя гетто, - это культура расщепленная и дискретная: «Расщепление представляет собой сложную стратегию защиты и дифференциации в колониальном дискурсе. Два противоречивых и независимых отноше- ния населяют одно и то же место: одно учитывает реальность, другое находится под влиянием инстинктов, которые отделяют эго от реальности. Это приводит к появлению множественных и противоречивых убеждений. Объясняющий момент множественного убеждения является одновременно и защитой от беспокойства о различиях, и сам по себе является продуктом дифференциации» [Bhabha $2004,132]$. Однако в отличие от западных городов культура сибирских городов в большей степени однородная.

Трактовка проникновения дискурса колонии и тюрьмы в дискурс «свободной», «доминантной», «официальной» культуры как процесса формирования гибридной культуры нам представляется уместной. Постколониальный дискурс давно вышел за рамки осмысления исключительно вопросов нации. Постколониальная оптика выступает своеобразным «всеобщим» для многих «особенных» маргинальных дискурсов современности. Ряд исследований использует постколониальную оптику для выявления власти и подчинения в культуpe, для осмысления шаблонов восприятия другой культуры.

Деконструкция и маргинальность - базовые понятия философии М. Фуко - удалены от «колониальной» темы. Между тем именно идеи М. Фуко и Ж. Деррида были взяты на вооружение открывателями постколониализма, увидевшими в их текстах ответы на свои вопросы. Прежде всего, деконструкция как прием, заимствованный у Ж. Деррида, был применен к образам и идентичностям, сопряженным с концептами нации, расы, Востока, Запада, империи, метрополии, колонии. Апробированный М. Фуко прием анализа институтов власти и систем подавления постколониальными исследователями переносится на отношения господства и подчинения в культуре во множестве вариантов. Даже в непериферийных культурах объяснительный потенциал приема Фуко позволил найти внутреннюю периферию. То, что вытесняется из современности как неактуальное или «враждебное», вызывающее «опасения», становится внутренней периферией в постколониальных исследованиях. Принципы воплощения такого вытеснения могут быть различны: от политкорректности, маргинализации, 
П.Л. Зайщев, С.Н. Оводова. Дискурс гибридной культуры: призонизация города (сибирский кейс)

музеификации отдельных травмирующих память событий до критики «цветным феминизмом» западного феминизма. Призонизация в данном контексте трактуется как сосуществование на границе, в одном пространстве региона тюремной культуры и «свободной» массовой культуры. Тюрьма и тюремный дискурс не изолированы в пространстве города, несмотря на то что заключенные изолированы от общества. Тюремный дискурс, будучи маргинальным, тем не менее проникает в пространство массовой культуры, создавая гибридные идентичности. Анализ призонизации демонстрирует, что гибридные формы культуры возникают не только на границе с другой нацией, другим государством, но и вскрывают наличие границ внутри города, несмотря на то что эти границы уже перестали быть непроницаемыми.

На наш взгляд, попытки сибирских городов дистанцироваться от своей колониальной истории, в контексте которой мы объясняем появление призонизации как феномена, обречены на неудачу. Призонизация затронула социальную, экономическую, культурную жизнь сибирских городов, ее маркеры включены в разговорный язык и индивидуальные жизненные стратегии. Возможно, если призонизацию нельзя преодолеть, ее можно использовать? Мы видим, как музеи сибирских городов пытаются привлечь посетителей обращением к тюремной и колониальной теме. Мы видим, как колониальная и тюремная тема сплетаются в общем дискурсивном пространстве освоения Сибири. Очевидно, что методологическая адаптация постколониальных исследований к Сибирской теме, например, как в работе В. Проскуриной, где анализируется «западный» (колониальный) взгляд на Сибирь [Проскурина 2017], позволит внести ясность и в тюремную, острожную тему. Учитывая успехи, достигнутые бывшими внешними колониями Европы в экономическом, социальном, культурном строительстве, мы предполагаем возможность развития и продуктивного использования сибирскими городами (в том числе и своей призонизированной истории), ведь их социальноэкономическая специфика в понятии «гибридная культура» наконец-то приобрела адекватное ей терминологическое воплощение.

\section{ПРИМЕЧАНИЕ}

${ }^{1}$ Исследование проводилось при поддержке гранта Президента РФ, проект МК-6373.2018.6 «Дискурс “глобального" и “локального” в современных философских концепциях культуры».

The study was conducted with the support of RF President Grant, project MK-6373.2018.6 "Discourse of 'global' and 'local' in modern philosophical concepts of culture”.

\section{СПИСОК ЛИТЕРАТУРЫ}

Берталанфи 1969 - Берталанфи Л. фон. Общая теория систем - обзор проблем и результатов // Системные исследования: ежегодник. М.: Наука, 1969. С. 30-54.

В Омске... web - В Омске заседание по делу о пытках в колонии ИК-7 решили провести в закрытом режиме // https:/www.novayagazeta.ru/ news/2018/05/18/141796-v-omske-zasedanie-podelu-o-pytkah-v-kolonii-ik-7-reshili-provesti-vzakrytom-rezhime.

Гельман, Хопф (ред.) 2003 - Гельман B., Хопф T. (ред.). Центр и региональные идентичности в России. СПб.: Изд-во Европ.ун-та в Санкт-Петербурге; М.: Летний сад, 2003.

Голошубин (ред.) 1914 - Справочная книга Омской епархии / сост., по поручению 7-го Епарх. съезда, свящ. села Новоселья, Тюкалин. уезда. Омск: Иртыш, 1914.

Город за “колючкой”... web - Город за “колючкой” Следственная тюрьма НКВД // http:// nkvd.tomsk.ru/projects/seversk_project.

Громова web - Громова Л. В исправительную колонию № 7 пустили наблюдателей // https:// newsomsk.ru/news/85066v_ispravitelnuyu_ koloniyu 7 pustili nablyudateley.

Довлатов 2006 - Довлатов С.Д. Собрание сочинений в 4 т. Т. 2. СПб.: Азбука-классика, 2006.

Достоевский 2008 - Достоевский Ф.М. Записки из Мертвого дома. М.: Директ-Медиа, 2008.

Мемориальный музей «Следственная тюрьма НКВД» web - Мемориальный музей «Следственная тюрьма НКВД» // http://nkvd.tomsk.ru.

Олейник 2001 - Олейник А.Н. Тюремная субкультура в России: от повседневной жизни до государственной власти. М.: Инфра-М, 2001.

Омский государственный литературный музей имени Ф.М. Достоевского web - Омский государственный литературный музей имени Ф.М. Достоевского // http://www.museum.ru/ M1894.

Проскурина 2017 - Проскурина В. Ландшафт империи: «Антидот» Екатерины II против «Пу- 
тешествия в Сибирь», или Границы европейской цивилизации // Новое литературное обозрение. 2017. № 2 (144). С. 9-32.

Сибирский тракт web - Сибирский тракт // http:// omsk-turinfo.com/index.php/sibirskij-trakt.

Тюремный замок web - Тюремный замок // http:// tiamz.ru/ru/museums/9.

Фромм 2008 - Фромм Э. Иметь или быть? М.: Директ-Медиа, 2008.

Фуко 2016 - Фуко М. Надзирать и наказывать. Рождение тюрьмы. М.: Ад Маргинем Пресс, 2016.

Bhabha 2004 - Bhabha H. K. The Location of Culture. L.; N.Y.: Routledge Classics, 2004.

Levan, Downing 2019 - Levan K., Downing S. Virtual Total Control: Escaping a Simulated Prison // Games and culture. 2019. Vol. 14. № 1. P. 46-66.

Martin 2018 - Martin P. Race, Colonial History and National Identity: Resident Evil 5 as a Japanese Game // Games and culture. 2018. Vol.13. № 6. P. 568-586.

McCann 2018 - McCann B. J. Prison Power: How Prison Influenced the Movement for Black Liberation // Rhetoric society quarterly. 2018. Vol. 48. № 5. P. 544-547.

Shigeoka 2018 - Shigeoka S. Being bad: My baby brother and the school-to-prison pipeline // Urban education. 2018. Vol. 53. № 9. P. 1182-1189.

Speed 2019 - Speed L. Renditions from the inside: Prison Songs, documusical and performative documentary // Continuum-jornal of media \& cultural studies. 2019. Vol. 33. № 3. P. 324-336.

\section{REFERENCES}

Bertalanffy L. von, 1969. General Systems Theory Overview of Problems and Results. System Studies: Yearbook. Moscow, Science, pp. 30-54.

In Omsk, the meeting on the case of torture in colony IK-7 decided to hold behind closed doors. URL: https:/www.novayagazeta.ru/news/2018/05/18/ 141796-v-omske-zasedanie-po-delu-o-pytkah-vkolonii-ik-7-reshili-provesti-v-zakrytom-rezhime.

Gelman V., Hopf T. (ed.), 2003. Center and regional identities in Russia. Saint Petersburg, European University Press in St. Petersburg; Moscow, Summer garden.

Goloshubin I. (ed.), 1914. Reference book of the Omsk Diocese. Omsk, Irtish.
City behind the "thorn" - the NKVD investigation prison. URL: http://nkvd.tomsk.ru/projects/ seversk_project.

Gromova L. In the correctional colony number 7 allowed observers. URL: https://newsomsk.ru/news/85066v_ispravitelnuyu_koloniyu_7_pustili_ nablyudateley.

Dovlatov S.D., 2006. Collected Works in 4 tons. T. 2. Saint Petersburg, Alphabet-classic.

Dostoevsky F.M., 2008. Notes from the House of the Dead. Moscow, Direct Media.

Memorial Museum "Investigation Prison of the NKVD”. URL: http://nkvd.tomsk.ru.

Oleynik A.N., 2001. Prison subculture in Russia: from everyday life to state power. Moscow, Infra-M.

Omsk State Literary Museum named after F.M. Dostoevsky. URL: http://www.museum.ru/ M1894.

Proskurina V., 2017. The landscape of the empire: "Antidot" of Catherine II against "Journey to Siberia", or the Borders of European Civilization. Novoe literaturnoe obozrenie, no. 2, pp. 9-32.

Siberian tract. URL: http://omsk-turinfo.com/ index.php/sibirskij-trakt.

Prison lock. URL: http://tiamz.ru/ru/museums/9.

Fromm E., 2008. To have or to be? Moscow, Direct Media.

Foucault M., 2016. Oversee and punish. The birth of the prison. Moscow, Ad Marginem Press.

Bhabha H.K., 2004. The Location of Culture. London; New York, Routledge Classics.

Levan K., Downing S., 2019. Virtual Total Control: Escaping a Simulated Prison. Games and culture, vol. 14, no. 1, pp. 46-66.

Martin P. Race, 2018. Colonial History and National Identity: Resident Evil 5 as a Japanese Game. Games and culture, vol. 13, no. 6, pp. 568-586.

McCann B.J., 2018. Prison Power: How Prison Influenced the Movement for Black Liberation, Rhetoric society quarterly, vol. 48, no. 5, pp. 544-547.

Shigeoka S., 2018. Being bad: My baby brother and the school-to-prison pipeline. Urban education, vol. 53, no. 9, pp. 1182-1189.

Speed L., 2019. Renditions from the inside: Prison Songs, documusical and performative documentary. Continuum-jornal of media \& cultural studies, vol. 33, no. 3, pp. 324-336. 
П.Л. Зайцุев, С.Н. Оводова. Дискурс гибридной культуры: призонизация города (сибирский кейс)

\section{Information about the Authors}

Pavel L. Zaitsev, Doctor of Sciences (Philosophy), Professor, Dean of the Faculty of Theology, Philosophy and World Cultures, Dostoevsky Omsk State University, Prosp. Mira, 55A, 644077 Omsk, Russian Federation, zaitsevpl@rambler.ru, https://orcid.org/0000-0003-3296-9839

Svetlana N. Ovodova, Candidate of Sciences (Philosophy), Associate Professor, Department of Theology and World Cultures, Dostoevsky Omsk State University, Prosp. Mira, 55A, 644077 Omsk, Russian Federation, sn_ovodova@rambler.ru, https://orcid.org/0000-0003-3408-1913

\section{Информация об авторах}

Павел Леонидович Зайцев, доктор философских наук, профессор, декан факультета теологии, философии и мировых культур, Омский государственный университет им. Ф.М. Достоевского, просп. Мира, 55А, 644077 г. Омск, Российская Федерация, zaitsevpl@rambler.ru, https://orcid.org/0000-0003-3296-9839

Светлана Николаевна Оводова, кандидат философских наук, доцент, доцент кафедры теологии и мировых культур, Омский государственный университет им. Ф.М. Достоевского, просп. Мира, 55А, 644077 г. Омск, Российская Федерация, sn_ovodova@rambler.ru, https://orcid.org/0000-0003-3408-1913 